DOI: 10.37943/AITU.2021.19.41.006
A. Kalikova MA, Senior-lecturer aigerim.kalikova@astanait.edu.kz, orcid.org/0000-0003-4429-0006 Astana IT University, Kazakhstan

\title{
S. Kusdavletov
}

MA, Senior-lecturer

sanzhar.kusdavletov@astanait.edu.kz,orcid.org/0000-0003-0286-776X

Astana IT University, Kazakhstan

\section{FEASIBILITY ANALYSIS OF AIR FLOATING DESIGN FOR ELECTRICITY GENERATION}

\begin{abstract}
In the past several decades, there were presented different innovative technologies rather than traditional wind turbines for renewable energy that uses wind kinetic energy and remains in the air through aerodynamic forces. Unlike wind turbines with towers, their systems operate in a flight, and they are connected to a foundation by a cable that either transmits the energy generated at the airfoil or transmits mechanical energy to the ground. Nowadays, there are several existing and developing technologies; however, each of them has limitations and challenges. This work will present an analysis of air floating design for electricity generation at high altitudes. It is a tethered wind turbine with a Balloon system, which has a simple controlling system, relatively higher efficiency, and low-cost technology. The concept of the design is to model the electricity generation device powered by clean renewable energy, mainly wind power. Base on the concept of kite or helium balloon to provide enough buoyancy to keep the device working at certain altitude. To increase the energy conversion efficiency and the feasibility of the device, it is mostly used in the country, open area. Despite high efficiency which needs further investigation, the designed device is moveable, pollution free and little space consumed.
\end{abstract}

Keywords: renewable energy, wind turbine, helium balloon, controlling system.

\section{Introduction}

Wind power has an important place in the future of the generation of electricity. However, by using wind turbines, we can face problems with potential safety hazards and environmental implications. Therefore, there is a high interest in an investigation and developing other forms of technologies for wind energy. Some of the examples can be kite or balloon power generation, flying electric generators, rotor kites [1]. They are a low-cost renewable energy technology with a low environmental impact.

The aim of the paper is to model a theoretical part of a tethered wind turbine with a balloon for electricity generation by using suitable environmentally harmless and low-cost materials. The modeling concept is to use tethered to the ground wind turbine (rotor with a shaft) that is lifted to the air due to the connected balloon, which will be filled with helium. A wind driven rotor with blades is affixed to the shaft, thereby enabling the shaft to impart rotational motion into the ground supported generator via tethered transmission cable. 


\section{Turbine and generator analysis}

Theory and principle. To obtain an accurate model, the model's inputs must be validated. Based on the altitude, ground wind speed and terrain condition, the relevant input can be calculated. Ambient conditions such as air pressure and temperature are function of altitude, and expressed as [1]:

$$
\begin{gathered}
T=T_{0}-L h \\
p=p_{0}\left(1-\frac{L h}{T_{0}}\right)^{\frac{g M}{R L}}
\end{gathered}
$$

where, $h$ is Altitude (m), $p$ - Pressure at altitude $\mathrm{h}, T$ - Temperature at altitude $\mathrm{h}, p_{0}$ - Sea level standard atmospheric pressure, $T_{0}$ - Sea level standard temperature, $g$ - Gravitational acceleration, $L$ - Temperature lapse rate, $R$ - Ideal gas constant, $M$ - Molar mass of dry air [1,2].

With acquired pressure and temperature at $h$ altitude, air density at the same altitude can be calculated. Air density is an important parameter as the power output of the turbine will be affected by it:

$$
\rho=\frac{p M}{R T}
$$

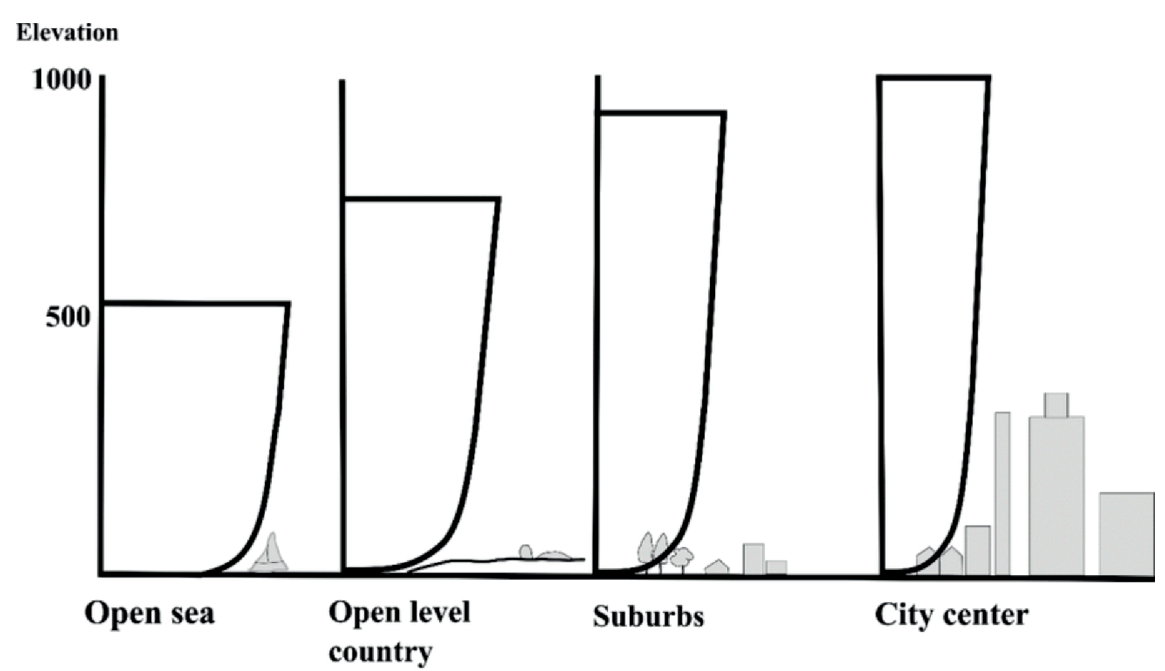

Fig.1. Wind Profile for different terrains [2]

As seen from Figure 1 [2], wind has different speeds at different altitudes. The gradient height of the open sea is much lower than the gradient height of the city center which indicates that the roughness length of the open sea is lower than the others. Theoretically, wind speed is affected by altitude and terrain conditions or friction, the higher the altitude, the more wind speed will be available with a more laminar flow [3]. The effective wind speed at altitude $h$ can be expressed via $v_{0}$ (wind speed at $h_{0}$ altitude) and $\alpha$ (friction Coefficient) (Table 1 ) as:

$$
v=v_{0}\left(\frac{h}{h_{0}}\right)^{\alpha}
$$


Table 1. Friction Coefficient

\begin{tabular}{|l|c|}
\hline \multicolumn{1}{|c|}{ Type of terrain } & Friction coefficient, $\alpha$ \\
\hline Smooth hard ground, smooth water & 0.10 \\
\hline Tall grass & 0.15 \\
\hline High crops, hedges & 0.20 \\
\hline Wooded ground with many trees & 0.25 \\
\hline Small town with trees & 0.30 \\
\hline Large city with tall buildings & 0.40 \\
\hline
\end{tabular}

Parameters of design and calculation. With all the input data calculated, it is time to determine the parameters of design for the wind turbine. Parameters such as a number of blades, a diameter of the rotor with blades, and tip speed ratio need to be determined in order to calculate the ideal dimension and furthermore the output power. Tip speed is the ratio [3] between the tangential velocity of the blade tip and the wind speed that expressed as:

$$
\text { Tip speed ratio }=\lambda=\frac{u}{v_{w}}=\frac{\text { tangential velocity of the blade tip }}{\text { wind speed }}
$$

With the tip speed ratio have been determined and wind speed is known, the angular velocity of the blades can be calculated. Furthermore, the tangential velocity, frequency and rotation per minute of the turbine can be found by $u=\omega r ; \omega=2 \pi f ; R P M=60 f$, where $u$ is tangential velocity of the blade tip, $v_{w}$ - wind speed, $\omega$ - angular velocity, $f$ - frequency, RPM - Rated rotating speed.

To calculate the ideal dimension of the blades, the chord length and angle of attack value for every blade section is required. But first, the resultant air velocity is needed.

$$
v_{\text {res }}=\sqrt{v_{\text {axial }}^{2}+u^{2}}
$$

With the resultant air velocity, the optimum chord length can be calculated. However, the optimum thickness of the blades is depending on the type of airfoil used. Both chord length and thickness should be calculated for every section of the blade, since every part of the blade experience a different wind speed [3].

$$
\begin{gathered}
C_{o p t}=\frac{16 \pi r v_{w}}{9 z c_{L} \lambda v_{\text {res }}} \\
T_{\text {opt }}=C_{\text {opt }} x \text { airfoil thickness ratio }
\end{gathered}
$$

where, $C_{\text {opt }}$ is Optimum chord length, $z$ - number of blades, $\mathrm{c}_{\mathrm{L}}-$ Coefficient of lift, $T_{\text {opt }}-$ Optimum airfoil thickness.

Another important parameter of the blade design is the pitch angle. The right pitch angle on every section of the blade will result in the right angle of attack depending on the airfoil type and therefore will optimize the lift force output [3,4]. Pitch angle $\beta$ - can be calculated via $\alpha$ - angle of attack as:

$$
\beta=\left(\tan ^{-1} \frac{v_{\text {axial }}}{r \omega}\right)-\alpha
$$

With the optimum angle of attach assured at every section of the blade, the lift force can be calculated. The coefficient of lift and lift to drag ratio are depending on the airfoil type, since both are characteristic of the airfoil. 


$$
\begin{gathered}
L=\frac{\rho v_{r e s}{ }^{2} A C_{L}}{2} \\
D=\text { lift to drag ratio } x L
\end{gathered}
$$

Next step is to calculate the resultant force on the blades by combining the lift force and the drag force that expressed as:

$$
F_{\text {res }}=\sqrt{L^{2}+D^{2}}
$$

The resultant force is not in the direction of rotation. Therefore, the angle difference between the resultant force and rotation direction need to be find with equation such as:

$$
\emptyset=90-(\alpha+\beta)+\tan ^{-1} \frac{D}{L}
$$

where, $\phi$ - is angle difference between resultant force and direction of rotation

After the angle is found, the tangential force and resultant drag force can easily be calculated [4]. Thus, by using expressions Tangential Force $=F_{\text {res }} \cos \emptyset$, Resulatant Drag $=F_{\text {res }} \sin \emptyset$, torsion $(T)$ and power $(P)$ can be calculated:

$$
\begin{gathered}
T=\text { Tangential Force } x r \\
P=T \omega
\end{gathered}
$$

Now that all steps and equations have been explained, several assumptions such as a number of blades, rotor diameter, tip speed ratio, ground wind speed, and airfoil type will be made. All calculation will be made based on the initial assumption and the value will be presented as calculations example.

Assumptions:

- Number of Blades: 3

- Diameter of rotor with blades: $2.5 \mathrm{~m}$

- Tip-speed ratio: 3

- Ground Wind Speed: 3.5 m/s

- Altitude: $200 \mathrm{~m}$

- Terrain: Trees $(\alpha=0.25)$

- Airfoil: NACA $4412\left(\alpha=9.75^{\circ} ; C_{L}=1.3\right.$; Thickness ratio $=12 \% ; \mathrm{L} / \mathrm{D}=25.3$ )

By using above formulas, we have the fallowing calculations:

$$
\begin{aligned}
& \rho=1.2 \mathrm{~kg} / \mathrm{m} 3 \\
& v_{m}=13.1 \mathrm{~m} / \mathrm{s} \\
& u=39.5 \mathrm{~m} / \mathrm{s} \\
& \omega=31.6 \mathrm{rad} / \mathrm{s} \\
& R P M=301.6 \mathrm{rpm} \\
& v_{\text {res }} \text { at tip of the blade }=40.45 \mathrm{~m} / \mathrm{s} \\
& C_{\text {opt }} \text { at tip of the blade }=0.194 \mathrm{~m} \\
& T_{\text {opt }} \text { at tip of the blade }=0.023 \mathrm{~m} \\
& \beta \text { at tip of the blade }=2.8^{\circ}
\end{aligned}
$$$$
L \text { at the last } 0.1 \mathrm{~m} \text { of the blades }=88.8 \mathrm{~N}
$$$$
D=3.5 \mathrm{~N}
$$$$
F_{\text {res }} \text { at the last } 0.1 \mathrm{~m} \text { of the blades }=88.9 \mathrm{~N}
$$$$
\phi=79.7^{\circ}
$$$$
\text { Tangential Force at the last } 0.1 \mathrm{~m} \text { of the }
$$$$
\text { blades }=15.8 \mathrm{~N}
$$$$
T=19.8 \mathrm{Nm}
$$$$
P \text { at the last } 0.1 \mathrm{~m} \text { of the blades }=625.7 \mathrm{~W}
$$

Parameters of a generator. The generator (Table 2) has been chosen based on the wind profile [5] of the certain area, there are more than 30 percent of the time the wind velocity that is more than $13 \mathrm{~m} / \mathrm{s}$. And with this wind condition, and the wind turbine model, the power can be caught by the 3 blade wind turbines are around 2-4 kW for 1-1.4 m long wind blade 
which scale the system in this range. So, there were selected the capacity of the generator to be $3 \mathrm{~kW}$ generator. And based on the available speed of $3 \mathrm{kw}$ generator, which are $100 \mathrm{rpm}$, $180 \mathrm{rpm}, 300 \mathrm{rpm}$ and so on, and it can adjust the tip speed ratio, limit the turbine wide. Finally, tip-speed ratio was set to be 3, with 2.5-meter diameter blades with rotor, which have $300 \mathrm{rpm}$ at $13 \mathrm{~m} / \mathrm{s}$ wind at 200 meters high. And base on the parameter of the engine [6], a chosen model of wind turbine should have rated wind velocity with $13 \mathrm{~m} / \mathrm{s}$.

Table 2. Selected parameters

\begin{tabular}{|l|l|}
\hline Rated Power(w) & 3000 \\
\hline Max Power(w) & 3500 \\
\hline Rated rotated speed(rpm) & 300 \\
\hline Top net weight(kg) & 39 \\
\hline Output Current & AC \\
\hline Start Torque(N*M) & $<0.1$ \\
\hline Generator & 3 phase permanent magnet synchronous generator \\
\hline Service Life & More Than 25 years \\
\hline Working Temperature & $-40{ }^{\circ} \mathrm{C}-80^{\circ} \mathrm{C}$ \\
\hline Efficiency & $>90 \%$ \\
\hline
\end{tabular}

\section{Modeling a helium balloon}

Analysis of force balance. The role of the balloon part is to provide the buoyancy force that allowss the whole system stays at a certain attitude. While designing the balloon part of the electricity-generating balloon, the following factors need to be taken into consideration: the density of air, the density of the gas filled in the balloon, the density of the surface material of the balloon, the mass of the whole system and the diameter of the balloon [7].

The volume of the balloon is

$$
V_{b}=\frac{4}{3} \pi R^{3}+\pi L R^{2}
$$

where, $\mathrm{R}$ is the radius of the balloon; $\mathrm{D}$ is the diameter; $\mathrm{L}$ is the length of the middle part. The buoyancy force [8] provided by the balloon part is

$$
F b=(\text { air }-\rho g a s) V b g
$$

where, $p_{\text {air }}$ is the density of the air; $p_{\text {gas }}$ is the density of the gas filled in the balloon; $V_{b}$ is the volume of the balloon; $g$ is the acceleration due to gravity.

The surface area of the balloon is

$$
A_{\text {surface }}=4 \pi R^{2}+\pi D L
$$

The self-weight of the balloon is

$$
G_{b}=A_{\text {surface }} * t * \rho_{\text {material }} * g
$$

where, $A_{\text {surface }}$ is the surface area of the balloon; $t$ is the thickness of the surface of the balloon; $p_{\text {material }}$ is the density of the balloon surface material; $\mathrm{g}$ is the acceleration due to gravity [9].

The air drag force acting on the balloon with $p_{\text {air }}$ (the density of the air), $A$ (the cross-section area of balloon), $v$ (wind speed) as fallowing: 


$$
F_{\text {bdrag }}=\frac{1}{2} \rho_{\text {air }} A v^{2}
$$

While analyzing the forces in the whole system, it is more convenient to consider them as an entire system. Therefore, the force analysis diagram is shown as follow (Figure 2):

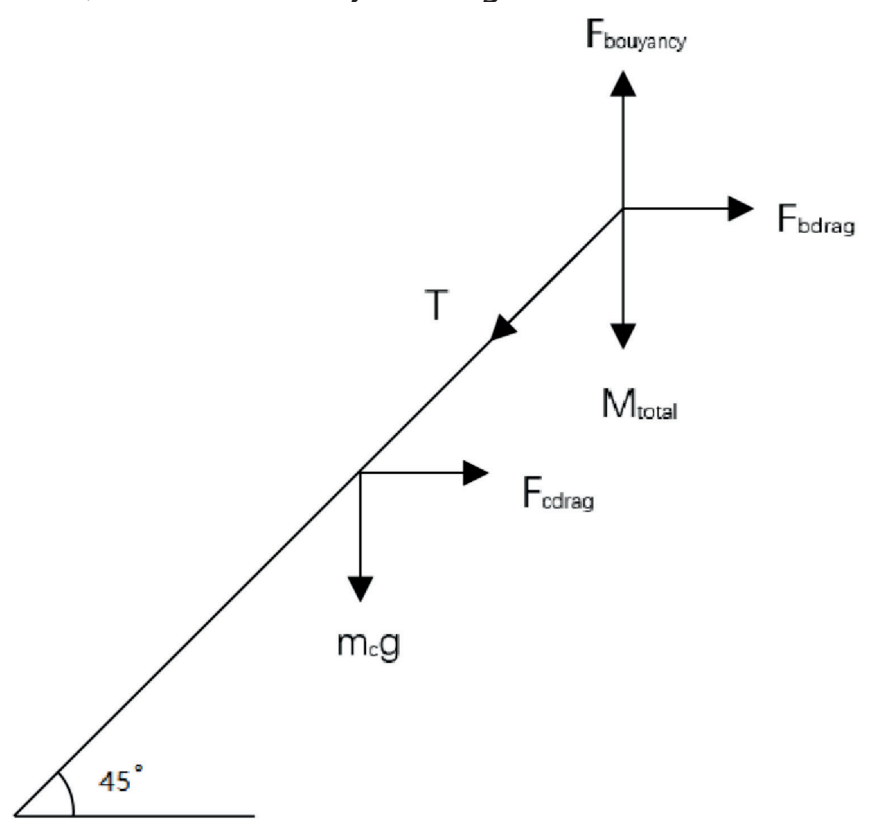

Fig. 2. Force analysis of the whole system

To achieve the force balance, the whole system must follow the force equilibrium equations:

$$
\begin{gathered}
F_{b}=G_{\text {total }}+T \sin \theta \\
F_{\text {bdrag }}+F_{\text {cdrag }}=T \cos \theta
\end{gathered}
$$

where, $G_{\text {total }}$ is the total weight of the whole system including balloon, turbine, generator,and cable; $F_{b d r a g}$ is the air drag force acting on the balloon; $F_{c d r a g}$ is the air drag force acting on the cable; $T$ is the tension force acting on the cable.

Based on the above equations, the buoyancy force provided by the balloon and the air drag force acting on the balloon can be calculated $[7,8]$. Thus, the total upwards force and the total air drag force of the system are obtained (Figure 3). Here, the limit angle is determined as 45 degrees, therefore, the total upwards force must be larger than the total air drag force [9]. 


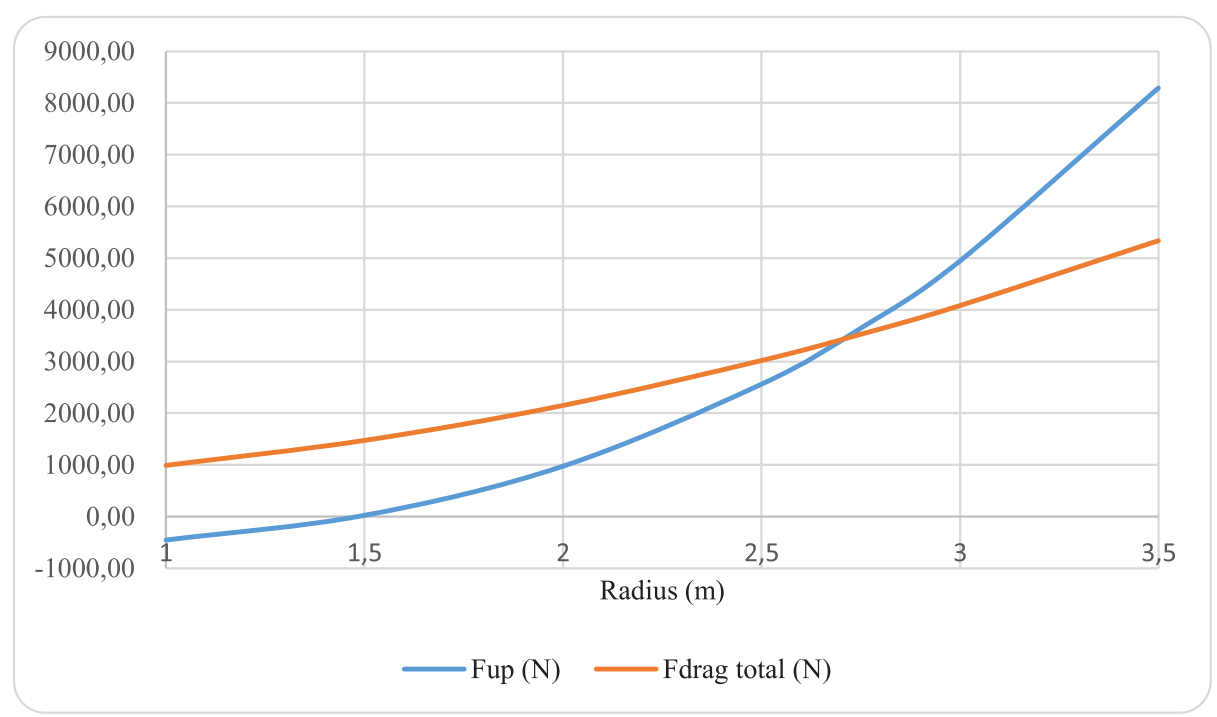

Fig. 3. Relation between Radius and Forces

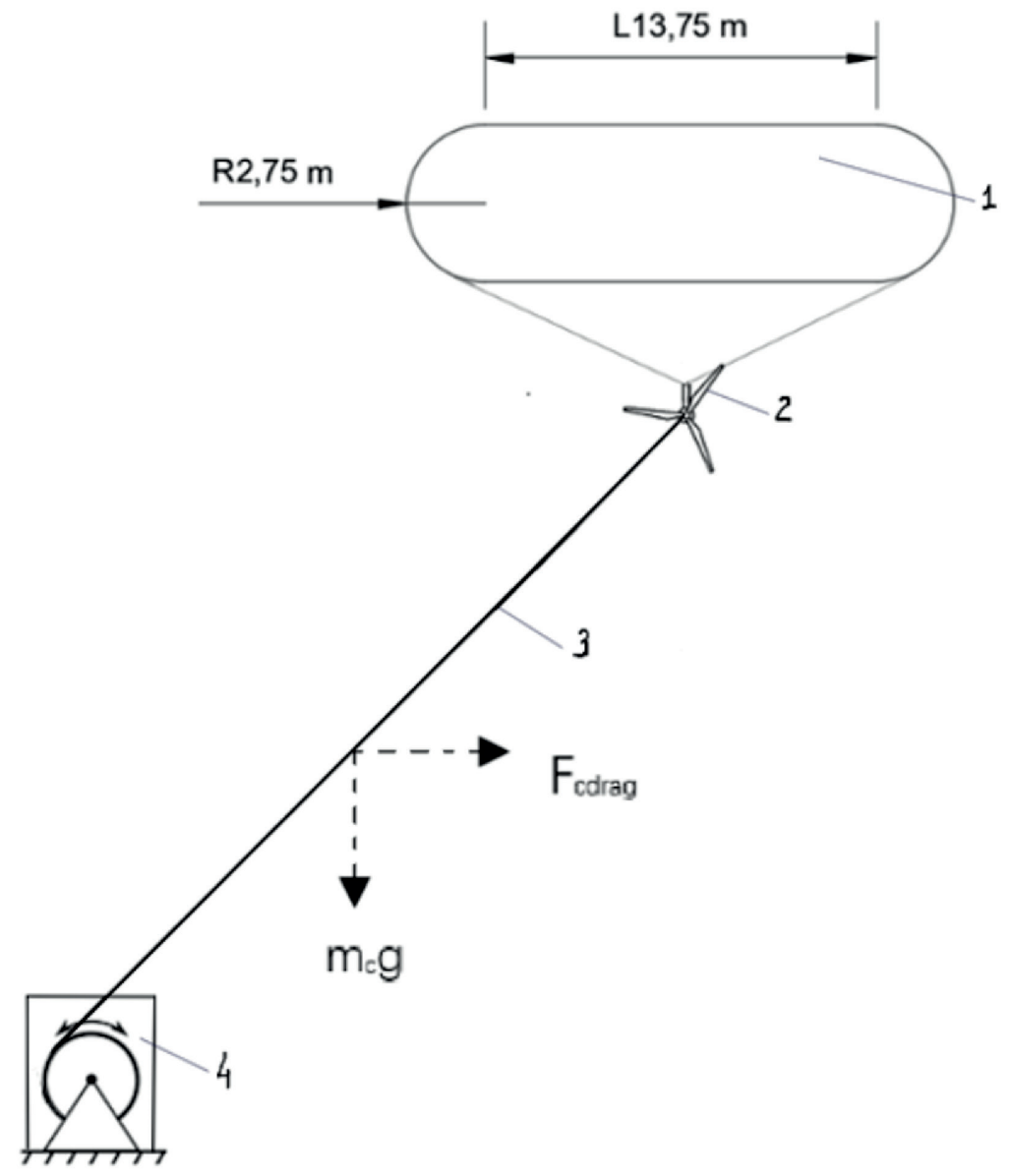

Fig. 4. Simplified design of a model.

1 - helium has ballon, 2 - rotor with blades, 3 - cables, 4 - ground station.

From the graph, it is shown that the upwards force equals to total air drag force when the radius is about $2.7 \mathrm{~m}$. However, for safety concerns, the radius is chosen as $2.75 \mathrm{~m}$. As the result, the tension force is $5071.56 \mathrm{~N}$, which is approximately half of the tensile capacity of the cable. Therefore, the whole system will be in a good state. 
However, there are still some risks that may result in the explosion or leak of the balloon. Thus, a safety mechanism should be installed in order to let the balloon land safely. The mechanism includes parachutes and landing stands.

Parameters of a balloon.

In this design, the gas filled in the balloon is Helium, which density is $0.1786 \mathrm{~g} / \mathrm{L}$. The surface of the balloon is made of the Cameron Balloon's Hyperlast fabric, which density is 1.14 $\mathrm{g} / \mathrm{m}^{3}$. The density of the air is $1.29 \mathrm{~kg} / \mathrm{m}^{3}$. The design height for the balloon is $200 \mathrm{~m}$. The rated wind speed is $13.8 \mathrm{~m} / \mathrm{s}$.

In the simplified embodiment of Figure 4, we can present a design. A balloon (1) filled with helium gas is tethered to the ground that is supported by a ground station (4) that includes energy conversion device, transformer. A wind driven rotor with blades (2) is affixed to the shaft, so that the winds aloft impart a rotating motion into the rotor, while the rotor imparts rotational motion into the shaft, thereby enabling the shaft to impart rotational motion into the ground supported generator via tethered cables (3). The produced energy can be used for consumption or to a set of batteries or to the power grid.

\section{Mechanical and transmission cables analysis}

The cable must perform two essential tasks - it must be strong enough to hold the balloon with the wind turbine and it must conduct electricity. As a result of the calculation, the material that is suitable for all calculation parameter is aluminum material (Table 3) for electricity transmission with a diameter $1.13 \mathrm{~mm}$ and Vectran fiber (Table 4) core for mechanical cable with $2 \mathrm{~mm}$ diameter $[9,10]$. Those two cables were combined in one.

Table 3. Safe electric currents via different materials and cross-section of wires

\begin{tabular}{|c|c|c|c|c|c|}
\hline $\begin{array}{c}\text { Cross-section wire } \\
\mathrm{mm}^{2} / \text { matter }\end{array}$ & 1.5 & 10 & 25 & $\begin{array}{c}\text { Resistance, } \\
\text { Ohm..m } \rho, 10^{-8}\end{array}$ & $\begin{array}{c}\text { Specific weight, } \gamma, \\
\mathrm{kg} / \mathrm{m}^{3}\end{array}$ \\
\hline Aluminum & 11 & 34 & 80 & 2.8 & 2700 \\
\hline Copper & 14 & 43 & 100 & 1.75 & 8930 \\
\hline Iron & & 17 & & 9.8 & 7900 \\
\hline
\end{tabular}

Table 4. Properties of Various Engineering Materials

\begin{tabular}{|c|c|c|c|}
\hline Material & Density $\mathbf{( g / \mathbf { c m } 3 )}$ & $\begin{array}{c}\text { Tensile } \\
\text { Strength } \mathbf{( G P a )}\end{array}$ & Specific Strength $\left.\mathbf{( k m}^{*}\right)$ \\
\hline Vectran $(\mathrm{HT})$ & 1.41 & 3.2 & 229 \\
\hline Aluminum & 2.8 & 0.6 & 22 \\
\hline Stainless Steel & 7.9 & 2.0 & 26 \\
\hline
\end{tabular}

For example, if the transmission energy is $N=100 \mathrm{~kW}$, speed of the mechanical transmission is $v=50 \mathrm{~m} / \mathrm{s}$, safety stress of artificial fiber is $\sigma=100 \mathrm{~kg} / \mathrm{mm}^{2}=10^{9} \mathrm{~N} / \mathrm{m}^{2}$, the cross-section area of the mechanical transmission cable is $s_{m}=2 \mathrm{~mm}^{2}=2 \times 10^{-6} \mathrm{~m}^{2}$. Diameter of the cable is $d=1.6 \mathrm{~mm}^{2} . F_{t}=N / v=10^{5} / 50=2000 \mathrm{~N}$. The critical factors for this transfer system are the weight, the length of the cable, its air drag, electric resistance and its coefficient of electric efficiency. 


\section{Conclusion}

In this project, both theoretical modelling and numerical calculations has been adopted to estimate and evaluate the performance of the product. Before modeling a tethered wind turbine with balloon, there was conducted a literature review base on all different existing design related to different kinds of kites, balloons, and relative electricity generators, wind technology. They differ in relation to the type of wing, which can be rigid or flexible; as to the location of the electric generator, which can be on the ground or suspended in the air. In terms of the aerodynamic power being exploited, there can be a drag or lift and as to how to control the flight of the airfoil, which depends on the number of cables and the position of sensors. Among the various concepts proposed over last the few decades, there was presented theoretical modeling of a tethered wind turbine with a balloon for electricity generation. The chosen model, according to presented calculations, showed a simple controlling system and it is quite high efficient by using suitable environmental harmless and low-cost materials. In this paper, we started to investigate the parameters of a turbine, followed by selection a generator with a helium balloon and completed with the theoretical model of the mechanical and transmission cables.

\section{References}

1. Darwish, A. S., \& Al-Dabbagh, R. (2020). Wind energy state of the art: present and future technology advancements. Renewable Energy and Environmental Sustainability, $5,7$.

2. Mendis, P., Ngo, T., Haritos, N., Hira, A., Samali, B., \& Cheung, J. (2007). Wind loading on tall buildings. Electronic Journal of Structural Engineering.

3. Hau, E. (2013). Wind turbines: fundamentals, technologies, application, economics. Springer Science \& Business Media.

4. Vermillion, C.; Glass, B.; Rein, A. (2013) Lighter-than-air wind energy systems. In Airborne Wind Energy; Springer, (pp. 325-380).

5. Hansen, J. T., Mahak, M., \& Tzanakis, I. (2021). Numerical modelling and optimization of vertical axis wind turbine pairs: A scale up approach. Renewable Energy, 171, 1371-1381.

6. Zhang, H. (2013). Kite modeling for higher altitude wind energy.

7. Bolonkin, A. (2014). Innovations and New Technologies (v. 2). Lulu. com.

8. Arturo Soriano, L., Yu, W., \& Rubio, J. D. J. (2013). Modeling and control of wind turbine. Mathematical Problems in Engineering, 2013.

9. Van Der Vlugt, R., Peschel, J., \& Schmehl, R. (2013). Design and experimental characterization of a pumping kite power system. In Airborne wind energy (pp. 403-425). Springer, Berlin, Heidelberg.

10. Segalini, A. (2021). An analytical model of wind-farm blockage. Journal of Renewable and Sustainable Energy, 13(3), 033307. 